\title{
The GAP function of a parametric mixed strong vector quasivariational inequality problem
}

\author{
Le Xuan Dai, Nguyen Van Hung, Phan Thanh Kieu
}

\begin{abstract}
The parametric mixed strong vector quasivariational inequality problem contains many problems such as, variational inequality problems, fixed point problems, coincidence point problems, complementary problems etc. There are many authors who have been studied the gap functions for vector variational inequality problem. This problem plays an important role in many fields of applied mathematics, especially theory of optimization. In this paper, we study a parametric gap function without the help of the nonlinear scalarization function for a parametric mixed strong vector quasivariational inequality problem (in short, (SQVIP)) in Hausdorff topological vector spaces. (SQVIP) Find

$\bar{x} \in K(\bar{x}, \gamma)$ and $\bar{z} \in T(\bar{x}, \gamma)$ such that$$
<\bar{z}, y-\bar{x}>+f(y, \bar{x}, \gamma) \in R_{+}^{n}, \forall y \in K(\bar{x}, \gamma),
$$

where we denote the nonnegative of $R^{n}$ by

$$
R_{+}^{n}=\left\{t=\left(t_{1}, t_{2}, \ldots, t_{n}\right)^{T} \in R^{n} \mid t_{i} \geq 0, i=1,2, \ldots, n\right\} .
$$

Moreover, we also discuss the lower semicontinuity, upper semicontinuity and the continuity for the parametric gap function for this problem. To the best of our knowledge, until now there have not been any paper devoted to the lower semicontinuity, continuity of the gap function without the help of the nonlinear scalarization function for a parametric mixed strong vector quasivariational inequality problem in Hausdorff topological vector spaces. Hence the results presented in this paper (Theorem 1.3 and Theorem 1.4) are new and different in comparison with some main results in the literature.

Manuscript Received on July 13 ${ }^{\text {th }}$, 2016. Manuscript Revised December $06^{\text {th }}, 2016$.

This research is funded by Ho Chi Minh City University of Technology - VNU-HCM under grant number T-KHUD-2016107.

Le Xuan Dai is with Department of Applied Mathematics, Ho Chi Minh City University of Technology - VNU-HCM, Vietnam National University - Ho Chi Minh City, Vietnam, Email: ytkadai@hcmut.edu.vn

Nguyen Van Hung is with Department of Mathematics, Dong Thap University, Cao Lanh City, Vietnam, Email: nvhung@dthu.edu.vn

Phan Thanh Kieu is with Department of Mathematics, Dong Thap University, Cao Lanh City, Vietnam, Email: ptkieu@dthu.edu.vn
Index Terms-Vector quasivariational inequality problem; parametric gap function; lower semicontinuity; upper semicontinuity, continuity.

\section{INTRODUCTION}

I et $X$ and $\Lambda$ be Hausdorff topological vector

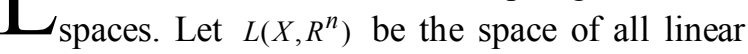
continuous operators from $X$ to $R^{n} . K: X \times \Lambda \rightarrow 2^{X}$, $T: X \times \Lambda \rightarrow 2^{L\left(X, R^{n}\right)}$ are set-valued mappings and let $f: X \times \Lambda \rightarrow R^{n} \quad$ be continuous single-valued mappings. For $\gamma \in \Lambda$ consider the following parametric mixed strong vector quasivariational inequality problem (in short, (SQVIP)).

(SQVIP) Find $\bar{x} \in K(\bar{x}, \gamma)$ and $\bar{z} \in T(\bar{x}, \gamma)$ such that

$$
<\bar{z}, y-\bar{x}>+f(y, \bar{x}, \gamma) \in R_{+}^{n}, \forall y \in K(\bar{x}, \gamma),
$$

where we denote the nonnegative of $R^{n}$ by

$$
R_{+}^{n}=\left\{t=\left(t_{1}, t_{2}, \ldots, t_{n}\right)^{T} \in R^{n} \mid t_{i} \geq 0, i=1,2, \ldots, n\right\} .
$$

Here the symbol ${ }^{T}$ denotes the transpose. We also denote

$$
\text { int } R_{+}^{n}=\left\{t=\left(t_{1}, t_{2}, \ldots, t_{n}\right)^{T} \in R^{n} \mid t_{i}>0, i=1,2, \ldots, n\right\} .
$$

For each $\gamma \in \Lambda$ we let $E(\gamma):=\{x \in X \mid x \in K(x, \gamma)\}$ and $\Phi: \Lambda \rightarrow 2^{X}$ be set-valued mapping such that $\Psi(\gamma)$ is the solution set of (SQVIP). Throughout the paper, we always assume that $\Psi(\gamma) \neq \varnothing$ for each $\gamma$ in the neighborhood $\gamma_{0} \in \Lambda$.

The parametric mixed strong vector quasivariational inequality problem contains many problems such as, variational nequality problems, fixed point problems, coincidence point problems, complementarity problems etc,. There are many authors have been studied the gap functions for vector variational inequality problem, see ([2]-[6], [8]-[10]) and the references therein.

The structure of our paper is as follows. In Section 1 of this article, we introduce the model vector quasivariational inequality problem and recall definitions for later uses. In Section 2, we establish the lower semicontinuity, the upper semicontinuity and the continuity for the gap 
function of parametric mixed strong vector quasivariational inequality problem.

\section{A. Preliminaries}

Next, we recall some basic definitions and their some properties.

Definition 1.1 (See [1], [7]) Let $X$ and $Z$ be Hausdorff topological vector spaces and $F: X \rightarrow 2^{Z}$ be a multifunction.

i) $F$ is said to be lower semicontinuous (lsc) at $x_{0}$ if $F\left(x_{0}\right) \cap U \neq \varnothing$ for some open set $U \subseteq Z$ implies the existence of a neighborhood $N$ of $x_{0}$ such that, for all $x \in N, F(x) \cap U \neq \varnothing$. An equivalent formulation is that: $F$ is lsc at $x_{0}$ if $\forall x_{\alpha} \rightarrow x_{0}, \quad \forall z_{0} \in F\left(x_{0}\right), \quad \exists z_{\alpha} \in F\left(x_{\alpha}\right), \quad z_{\alpha} \rightarrow z_{0}$. $F$ is said to be lower semicontinuous in $X$ if it is lower semicontinuous at each $x_{0} \in X$.

ii) $F$ is said to be upper semicontinuous (usc) at $x_{0}$ if for each open set $U \supseteq F\left(x_{0}\right)$, there is a neighborhood $N$ of $x_{0}$ such that $U \supseteq F(N) . F$ is said to be upper semicontinuous in $X$ if it is upper semicontinuous at each $x_{0} \in X$.

iii) $F$ is said to be continuous at $x_{0}$ if it is both lsc and usc at $x_{0} . F$ is said to be continuous at $x_{0}$ if it is continuous at each $x_{0} \in X$.

iv) $F$ is said to be closed at $x_{0} \in X$ if and only if $\forall x_{n} \rightarrow x_{0}, \quad \forall y_{n} \rightarrow y_{0}$ such that $y_{n} \in F\left(x_{n}\right)$, we have $y_{0} \in F\left(x_{0}\right) . F$ is said to be closed in $X$ if it is closed at each $x_{0} \in X$.

Lemma 1.1 (See [1], [7]) If $F$ has compact values, then $F$ is usc at $x_{0}$ if and only if, for each net $\left\{x_{\alpha}\right\} \subseteq X$ which converges to $x_{0}$ and for each net $\left\{y_{\alpha}\right\} \subseteq F\left(x_{\alpha}\right)$, there are $y \in F(x)$ and a subnet $\left\{y_{\beta}\right\}$ of $\left\{y_{\alpha}\right\}$ such that $y_{\beta} \rightarrow y$.

\section{B. Main Results}

In this section, we introduce the parametric gap functions for parametric mixed strong vector quasivariational inequality problem, then we study some properties of this gap function.

Definition 1.2 A function $h: X \times \Lambda \rightarrow R$ is said to be a parametric gap function of (SQVIP) if it satisfies the following properties [i)]

i) $h(x, \gamma) \geq 0$ for all $x \in E(\gamma)$.

i) $h\left(x_{0}, \gamma_{0}\right)=0$ if and only if $x_{0} \in \Psi\left(\gamma_{0}\right)$.

Now we suppose that $K(x, \gamma)$ and $T(x, \gamma)$ are compact sets for any $(x, \gamma) \in X \times \Lambda$. We define function $h: X \times \Lambda \rightarrow R$ as follows

$$
h(x, \gamma)=\min _{z \in T(x, \gamma)} \max _{y \in K(x, \gamma)}(<z, x-y>-f(y, x, \gamma))_{i}
$$

where $\quad(<z, x-y>-f(y, x, \gamma))_{i} \quad$ is the $i$ th component of $\langle z, x-y\rangle-f(y, x, \gamma), \quad i=1,2, \ldots, n$.

Since $K(x, \gamma)$ and $T(x, \gamma)$ are compact sets, $h(x, \gamma)$ is well-defined.

In the following, we will always assume that $f(x, x, \gamma)=0$ for all $x \in E(\gamma)$.

Theorem 1.2 The function $h(x, \gamma)$ defined by (1) is a parametric gap function for the (SQVIP).

Proof. We define a function $h_{1}: X \times L\left(X, R^{n}\right) \rightarrow R^{n}$ as follows

$$
h_{1}(x, z)=\max _{y \in K(x, \gamma) 1 \leq i \leq n} \max _{(<z, x-y>-f(y, x, \gamma))_{i},}
$$

where $x \in E(\gamma), z \in T(x, \gamma)$.

i) It is easy to see that $h_{1}(x, z) \geq 0$. Suppose to the contrary that there exists $x_{0} \in E(\gamma)$ and $z_{0} \in T\left(x_{0}, \gamma\right)$ such that $h_{1}\left(x_{0}, z_{0}\right)<0$, then

$$
\begin{gathered}
0>h_{1}\left(x_{0}, z_{0}\right)=\max _{y \in K\left(x_{0}, \gamma\right)} \max _{1 \leq i \leq n}\left(<z_{0}, x-y>-f\left(y, x_{0}, \gamma\right)\right)_{i} \\
\geq \max _{1 \leq i \leq n}\left(<z_{0}, x-y>-f\left(y, x_{0}, \gamma\right)\right)_{i}, \forall y \in K\left(x_{0}, \gamma\right),
\end{gathered}
$$

which is impossible when $y=x_{0}$. Hence,

$$
h_{1}(x, z)=\max _{y \in K(x, \gamma)} \max _{1 \leq i \leq n}(<z, x-y>-f(y, x, \gamma))_{i} \geq 0,
$$

where $x \in E(\gamma), z \in T(x, \gamma)$. Thus, since $z \in T(x, \gamma)$ is arbitrary, we have

$$
h(x, \gamma)=\min _{z \in T(x, \gamma)} \max _{y \in K(x, \gamma)}(<z, x-y>-f(y, x, \gamma))_{i} \geq 0 .
$$

ii) By definition, $h\left(x_{0}, \gamma_{0}\right)=0$ if and only if there exists $z_{0} \in T\left(x_{0}, \gamma_{0}\right)$ such that $h_{1}\left(x_{0}, z_{0}\right)=0$, i.e.,

$$
\max _{y \in K\left(x_{0}, \gamma_{0}\right)} \max _{1 \leq i \leq n}\left(<z_{0}, x_{0}-y>-f\left(y, x_{0}, \gamma_{0}\right)\right)_{i}=0,
$$

for $x_{0} \in E\left(\gamma_{0}\right)$ if and only if, for any $y \in K\left(x_{0}, \gamma_{0}\right)$,

$$
\max _{1 \leq i \leq n}\left(<z_{0}, x_{0}-y>-f\left(y, x_{0}, \gamma_{0}\right)\right)_{i} \leq 0,
$$

namely, there is an index $1 \leq i_{0} \leq n$, such that $\left(<z_{0}, x_{0}-y>-f\left(y, x_{0}, \gamma_{0}\right)\right)_{i_{0}} \geq 0$, which is equivalent to

$$
<z_{0}, x_{0}-y>-f\left(y, x_{0}, \gamma_{0}\right) \in R_{+}^{n}, \forall y \in K\left(x_{0}, \gamma_{0}\right),
$$

that is, $x_{0} \in \Psi\left(\gamma_{0}\right)$.

Remark 1.1 As far as we know, there have not been any works on parametric gap functions for mixed strong vector quasiequilibrium problems, and hence our the parametric gap functions is new and cannot compare with the existing ones in the literature. 
Example 1.1 Let $X=R, n=2, \Lambda=[0,1]$,

$K(x, \gamma)=[0,1], \quad T(x, \gamma)=\left[\frac{1}{2}, 3 \gamma^{2} x^{2}+x^{4}\right]$ and

$f(y, x, \gamma)=0$. Now we consider the problem $(Q V I P)$,

finding $x \in K(x, \gamma)$ and $z \in T(x, \gamma)$ such that

$$
<z, y-x>+f(y, x, \gamma)=\left(\frac{1}{2}(y-x),\left(3 \gamma^{2} x^{2}+x^{4}\right)(y-x)\right)
$$

$\in R_{+}^{2}$. It follows from a direct computation $\Psi(\gamma)=\{0\}$ for all $\gamma \in[0,1]$. Now we show that $h(.,$.$) is$ a parametric gap function of (SQVIP). Indeed, taking $e=(1,1) \in \operatorname{int} R_{+}^{n}$, we have

$$
\begin{aligned}
& h(x, \gamma)=\min _{z \in T(x, \gamma)} \max _{y \in K(x, \gamma) 1 \leq i \leq n} \max _{1<z, x-y>-f(y, x, \gamma))_{i}}\left(\begin{array}{rr}
0, & \text { if } x=0
\end{array}\right. \\
= & \max _{y \in K(x, \gamma)}\left(\left(3 \gamma^{2} x^{2}+x^{4}\right)(x-y)\right)=\left\{\begin{aligned}
2 & \\
\gamma^{2} x^{3}+x^{5}, & \text { if } x \in(0,1]
\end{aligned}\right.
\end{aligned}
$$

Hence, $h(. .$.$) is a parametric gap function of$ (SQVIP).

The following Theorem 1.3 gives sufficient condition for the parametric gap function $h(.,$.$) is$ continuous in $X \times \Lambda$.

Theorem 1.3 Consider (SQVIP). If the following conditions hold:

i) $K($...) is continuous with compact values in $X \times \Lambda$;

ii) $T($...) is upper semicontinuous with compact values in $X \times \Lambda$.

Then $h(.,$.$) is lower semicontinuous in X \times \Lambda$.

Proof. First, we prove that $h(.,$.$) is lower$ semicontinuous in $X \times \Lambda$. Indeed, we let $a \in R$ and suppose that $\left\{\left(x_{\alpha}, \gamma_{\alpha}\right)\right\} \subseteq X \times \Lambda \quad$ satisfying $h\left(x_{\alpha}, \gamma_{\alpha}\right) \leq a, \forall \alpha$ and $\left(x_{\alpha}, \gamma_{\alpha}\right) \rightarrow\left(x_{0}, \gamma_{0}\right)$ as $\alpha \rightarrow \infty$. It follows that $h\left(x_{\alpha}, \gamma_{\alpha}\right)=$

$$
=\min _{z \in T\left(x_{\alpha}, \gamma_{\alpha}\right)} \max _{y \in K\left(x_{\alpha}, \gamma_{\alpha}\right)} \max _{1 \leq i \leq n}\left(<z, x_{\alpha}-y>-f\left(y, x_{\alpha}, \gamma_{\alpha}\right)\right)_{i} \leq a .
$$

We define the function $h_{0}: X \times L\left(X, R^{n}\right) \times \Lambda \rightarrow R$ by

$$
h_{0}(x, z, \gamma)=\max _{y \in K(x, \gamma)} \max _{1 \leq i \leq n}(<z, x-y>-f(y, x, \gamma))_{i} \in E(\gamma) .
$$

Since $g$ and $f$ are continuous, we have $(<z, x-y\rangle-f(y, x, \gamma))_{i}$ is continuous, and since $K(.,$. is continuous with compact values in $X \times \Lambda$. Thus, by Proposition 19 in Section 3 of Chapter 1 [1] we can deduce that $h_{0}(x, z, \gamma)$ is continuous. By the compactness of $T\left(x_{\alpha}, \gamma_{\gamma}\right)$, there exists $z_{\alpha} \in T\left(x_{\alpha}, \gamma_{\gamma}\right)$ such that $h\left(x_{\alpha}, \gamma_{\alpha}\right)=$

$$
\begin{gathered}
=\min _{z \in T\left(x_{\alpha}, \gamma_{\alpha}\right)} \max _{y \in K\left(x_{\alpha}, \gamma_{\alpha}\right)} \max _{1 \leq i \leq n}\left(<z, x_{\alpha}-y>-f\left(y, x_{\alpha}, \gamma_{\alpha}\right)\right)_{i} \\
=h_{0}\left(x_{\alpha}, z_{\alpha}, \gamma_{\alpha}\right)= \\
=\max _{y \in K\left(x_{\alpha}, \gamma_{\alpha}\right)} \max _{1 \leq i \leq n}\left(<z, x_{\alpha}-y>-f\left(y, x_{\alpha}, \gamma_{\alpha}\right)\right)_{i} \leq a .
\end{gathered}
$$

Since $K(.,$.$) is lower semicontinuous in X \times \Lambda$, for any $y_{0} \in K\left(x_{0}, \gamma_{0}\right)$, there exists $y_{\alpha} \in K\left(x_{\alpha}, \lambda_{\alpha}\right)$ such that $y_{\alpha} \rightarrow y_{0}$. For $y_{\alpha} \in K\left(x_{\alpha}, \lambda_{\alpha}\right)$, we have

$$
\max _{1 \leq i \leq n}\left(<z, x_{\alpha}-y_{\alpha}>-f\left(y_{\alpha}, x_{\alpha}, \gamma_{\alpha}\right)\right)_{i} \leq a \text {. }
$$

Since $T(.,$.$) is upper semicontinuous with$ compact values in $X \times \Lambda$, there exists $z_{0} \in T\left(x_{0}, \gamma_{0}\right)$ such that $z_{\alpha} \rightarrow z_{0}$ (taking a subnet $\left\{z_{\beta}\right\}$ of $\left\{z_{\alpha}\right\}$ if necessary) as $\quad \alpha \rightarrow \infty$. Since $\max (<z, x-y>-f(y, x, \gamma))_{i}$ is continuous. Taking the $1 \leq i \leq n$

limit in (2), we have

$$
\max _{1 \leq i \leq n}\left(<z_{0}, x_{0}-y_{0}>-f\left(y_{0}, x_{0}, \gamma_{0}\right)\right)_{i} \leq a .
$$

Since $y \in K\left(x_{0}, \gamma_{0}\right)$ is arbitrary, it follows from (3) that

$$
\begin{gathered}
h_{0}\left(x_{0}, z_{0}, \gamma_{0}\right)= \\
=\max _{y \in K\left(x_{0}, \gamma_{0}\right)} \max _{1 \leq i \leq n}\left(<z_{0}, x_{0}-y>-f\left(y, x_{0}, \gamma_{0}\right)\right)_{i} \leq a .
\end{gathered}
$$

and so, for any $z \in T\left(x_{0}, \gamma_{0}\right)$, we have $h\left(x_{0}, \gamma_{0}\right)=$

$$
=\min _{z \in T\left(x_{0}, \gamma_{0}\right)} \max _{y \in K\left(x_{0}, \gamma_{0}\right)} \max _{1 \leq i \leq n}\left(<z, x_{0}-y>-f\left(y, x_{0}, \gamma_{0}\right)\right)_{i} \leq a .
$$

This proves that, for $a \in R$, the level set $\{(x, \gamma) \in X \times \Lambda \mid h(x, \gamma) \leq a\}$ is closed. Hence, $h(. .$,$) is$ lower semicontinuous in $X \times \Lambda$.

Theorem 1.4 Consider (SQVIP). If the following conditions hold: [i)] $X \times \Lambda$;

1. $K(. .$,$) is continuous with compact values in$

2. $T(. .$.$) is continuous with compact values in$ $X \times \Lambda$.

Then $h(.,$.$) is continuous in X \times \Lambda$.

Proof. Now, we need to prove that $h(.,$.$) is upper$ semicontinuous in $X \times \Lambda$. Indeed, let $a \in R$ and suppose that $\left\{\left(x_{\alpha}, \gamma_{\alpha}\right)\right\} \subseteq X \times \Lambda \quad$ satisfying $h\left(x_{\alpha}, \gamma_{\alpha}\right) \geq a$, for all $\alpha$ and $\left(x_{\alpha}, \gamma_{\alpha}\right) \rightarrow\left(x_{0}, \gamma_{0}\right)$ as $\alpha \rightarrow \infty$, then $h\left(x_{\alpha}, \gamma_{\alpha}\right)=$

$$
=\min _{z \in T\left(x_{\alpha}, \gamma_{\alpha}\right)} \max _{y \in K\left(x_{\alpha}, \gamma_{\alpha}\right)} \max _{1 \leq i \leq n}\left(<z, x_{\alpha}-y>-f\left(y, x_{\alpha}, \gamma_{\alpha}\right)\right)_{i} \geq a
$$

and so 


$$
\max _{y \in K\left(x_{\alpha}, \gamma_{\alpha}\right)} \max _{1 \leq i \leq n}\left(<z, x_{\alpha}-y>-f\left(y, x_{\alpha}, \gamma_{\alpha}\right)\right)_{i} \geq a, \forall z \in T\left(x_{\alpha, \gamma_{\alpha}}\right)
$$

\section{REFERENCES}

Since $T(.,$.$) is lower semicontinuous with$ compact values in $X \times \Lambda$, for any $z_{0} \in T\left(x_{0}, \gamma_{0}\right)$, there exists $z_{\alpha} \in T\left(x_{\alpha}, \gamma_{\alpha}\right)$ such that $z_{\alpha} \rightarrow z_{0}$ as $\alpha \rightarrow \infty$.

Since $z_{\alpha} \in T\left(x_{\alpha}, \gamma_{\alpha}\right)$, it follows (4) that

$$
\max _{y \in K\left(x_{\alpha}, \gamma_{\alpha}\right)} \max _{1 \leq i \leq n}\left(<z_{\alpha}, x_{\alpha}-y>-f\left(y, x_{\alpha}, \gamma_{\alpha}\right)\right)_{i} \geq a,
$$

Since $f$ and $g$ are continuous, so $\max _{1 \leq i \leq n}\left(<z_{\alpha}, x-y>-f(y, x, \gamma)\right)_{i}$ is continuous. By the compactness of $K(.,$.$) there exists y_{\alpha} \in K\left(x_{\alpha}, \gamma_{\gamma}\right)$ such that

$$
\max _{1 \leq i \leq n}\left(<z_{\alpha}, x_{\alpha}-y_{\alpha}>-f\left(y_{\alpha}, x_{\alpha}, \gamma_{\alpha}\right)\right)_{i} \geq a
$$

Since $K(.,$.$) is upper semicontinuous with$ compact values, there exists $y_{0} \in K\left(x_{0}, \gamma_{0}\right)$ such that $y_{\alpha} \rightarrow y_{0} \quad$ (taking a subnet $\left\{y_{\beta}\right\}$ of $\left\{y_{\alpha}\right\}$ if necessary) as $\quad \alpha \rightarrow \infty$. Since $\max _{1 \leq i \leq n}\left(<z, x-y_{\alpha}>-f(y, x, \gamma)\right)_{i}$ is continuous. Taking $1 \leq i \leq n$

limit in (6), we have

$$
\max _{1 \leq i \leq n}\left(<z_{0}, x_{0}-y_{0}>-f\left(y_{0}, x_{0}, \gamma_{0}\right)\right)_{i} \geq a .
$$

For any $y \in K\left(x_{0}, \gamma_{0}\right)$, we have

$$
\max _{y \in K\left(x_{0}, \gamma_{0}\right)} \max _{1 \leq i \leq n}\left(<z_{0}, x_{0}-y>-f\left(y, x_{0}, \gamma_{0}\right)\right)_{i} \geq a .
$$

Since $z \in T\left(x_{0}, \gamma_{0}\right)$ is arbitrary, it follows from (8) that $h\left(x_{0}, \gamma_{0}\right)=\mathrm{f}$

$$
=\min _{z \in T\left(x_{0}, \gamma_{0}\right)} \max _{y \in K\left(x_{0}, \gamma_{0}\right)} \max _{1 \leq i \leq n}\left(<z, x_{0}-y>-f\left(y, x_{0}, \gamma_{0}\right)\right)_{i} \geq a
$$

This proves that, for $a \in R$, the level set $\{(x, \gamma) \in X \times \Lambda \mid h(x, \gamma) \geq a\}$ is closed. Hence, $h(. .$,$) is$ upper semincontinuous in $X \times \Lambda$.

\section{Conclusion}

To the best of our knowledge, until now there have not been any paper devoted to the lower semicontinuity, continuity of the gap function without the help of the nonlinear scalarization function for a parametric mixed strong vector quasivariational inequality problem in Hausdorff topological vector spaces. Hence our results, Theorem 1.3 and Theorem 1.4 are new. 


\title{
Hàm GAP cho bài toán bất đẳng thức tựa biến phân véc tơ tham số hỗn hợp mạnh
}

\author{
Lê Xuân Đại, Nguyễn Văn Hưng, Phan Thanh Kiều
}

Tóm tắt - Bài toán bất đẳng thức tựa biến phân véc tơ tham số hỗn hợp mạnh bao gồm nhiều vấn đề như bài toán bất đẳng thức biến phân, bài toán điểm bất động, bài toán điểm trùng lặp, bài toán bù nhau, v.v. Có nhiều tác giả đang nghiên cứu tìm hàm gap cho bài toán bất đẳng thức biến phân véc tơ. Bài toán này đóng vai trò quan trọng trong nhiều lĩnh vực toán ứng dụng, đặc biệt là lý thuyết tối ưu. Trong bài báo này, chúng tôi nghiên cứu hàm gap tham số với sự hố trợ của hàm phi tuyến vô hướng cho bài toán bất đẳng thức tựa biến phân véc tơ tham số hỗn hợp mạnh (viết tắt (SQVIP)) trong không gian tô pô véc tơ Hausdorff. (SQVIP) Tìm

$$
\begin{aligned}
& \bar{x} \in K(\bar{x}, \gamma) \text { và } \bar{z} \in T(\bar{x}, \gamma) \text { sao cho } \\
& <\bar{z}, y-\bar{x}>+f(y, \bar{x}, \gamma) \in R_{+}^{n}, \forall y \in K(\bar{x}, \gamma), \\
& \text { với } \\
& R_{+}^{n}=\left\{t=\left(t_{1}, t_{2}, \ldots, t_{n}\right)^{T} \in R^{n} \mid t_{i} \geq 0, i=1,2, \ldots, n\right\} .
\end{aligned}
$$

Ngoài ra, chúng tôi cũng thảo luận tính nửa liên tục dưới, nửa liên tục trên và tính liên tục của hàm gap tham số cho bài toán này. Theo những hiểu biết của mình, chúng tôi cho rằng tới nay chưa từng có bài báo nào nghiên cứu tính nửa liên tục dưới, tính liên tục của hàm gap mà không cần sự trợ giúp của hàm phi tuyến vô hướng đối với bài toán bất đẳng thức tựa biến phân véc tơ tham số hỗn hợp mạnh trong không gian tô pô véc tơ Hausdorff. Do đó những kết quả được trình bày trong bài báo này (Định lý 1.3 và Định lý 1.4 ) là mới và khác biệt so với một số kết quả chính trong tài liệu tham khảo

Tù̀ khóa - Bài toán bất đẳng thức tựa biến phân vécto; hàm gap tham số; tính nửa liên tục dưới; tính nửa liên tục trên, tính liên tục. 